\title{
Silicon Microsegregation in 14K Yellow Gold Jewelry Alloys
}

\author{
John C McCloskey, Shankar Aithal and Paul R Welch \\ Stuller Settings Inc, Technology Department / Metals Division, 302 Rue Louis XIV, Lafayette, LA 70508, USA \\ E-mail:john_mccloskey@STULLER.COM
}

Received: 20 November 2000

Phase equilibria have been used to construct a simplified model of 14 karat (14K) yellow jewelry alloys. In this model, silicon has a reduced solubility in solid $14 \mathrm{~K}(\mathrm{Au}-\mathrm{Cu}-\mathrm{Ag}-\mathrm{Zn})$ alloys compared to its solubility in pure copper. This reduced solubility results in low values of the partition coefficient for silicon in these alloys. The microsegregation of silicon in $14 \mathrm{~K}$ yellow gold jewelry casting alloys was evaluated based on the principles of non-equilibrium solidification. The dynamics of non-equilibrium freezing described by the Gulliver-Scheil equation predict the build-up of silicon in the liquid phase to such an extent that unexpected, silicon-rich phases and compounds may appear in the solidification structure. These phases can have deleterious effects on mechanical properties and limit the use of certain types of grain refiners in (Au$\mathrm{Cu}-\mathrm{Ag}-\mathrm{Zn}$ ) families of alloys. The practical limits of silicon levels in $14 \mathrm{~K}$ yellow gold alloys which do not allow the formation of $\mathrm{Cu}-\mathrm{Si}$ intermetallics are estimated.

There are mixed messages and opinions in the jewelry industry about the role of silicon as an alloying element in karat gold casting alloys. Dieter Ott (1) summarized the situation very well when he stated that "the use of silicon is almost a philosophical question (in karat gold alloys)."

Silicon is known to perform useful deoxidation and 'brightening' functions. It is also known to increase the apparent fluidity of molten alloys and help in the production of investment castings which faithfully replicate intricate details in patterns. However, silicon promotes the development of large grains in cast structures and in high concentrations can cause the formation of low melting phases or precipitates which reduce mechanical properties. Figure 1 shows the brittle fractures associated with coarse grains in 14 karat $(14 \mathrm{~K})$ yellow gold alloys containing silicon.

Two recent studies of silicon-deoxidized $9 \mathrm{~K}$ and $14 \mathrm{~K}$ yellow golds indicate that the behaviour of silicon in these alloys is linked to the total precious metal content in a karat gold alloy. Normandeau (2) studied the effects of silicon in 10,14 , and $18 \mathrm{~K}$ yellow gold jewelry alloys. In his study, the effect of silicon was correlated with the total concentrations of gold and silver in a casting alloy. The results indicate that as the total amount of gold and silver in a jewelry casting alloy increases, the alloy demonstrates loss of ductility and embrittlement when silicon exceeds a critical level. In other words, the alloys become less tolerant of silicon as caratage increases. Silicon-rich particles were observed on the grain boundaries of $14 \mathrm{~K}$ fracture specimens when nominal silicon levels exceeded 0.175 wt $\%$ (3). Silicon concentration greater than 0.050 $\mathrm{wt} \%$ in $18 \mathrm{~K}$ alloys resulted in severely embrittled specimens for tensile testing.

Grice (4) studied silicon-deoxidized low karat golds and reported the appearance of an alloy phase in the grain boundaries of alloys with silicon contents in the range of $0.10-0.75 \mathrm{wt} \%$. He concluded that $9 \mathrm{~K}$ alloys containing high concentrations of silicon can be made to fail during devesting operations because of cracking and hot tearing effects caused by these grain boundary segregates.

The results of these two investigations indicate that silicon is demonstrating a unique behaviour when present as an alloying element in yellow karat golds: silicon is more severely segregated in karat golds than might be expected. An investigation was undertaken at Stuller Settings Inc to evaluate the microsegregation of silicon during freezing events in jewelry alloys.

This research project was structured around: (1) 

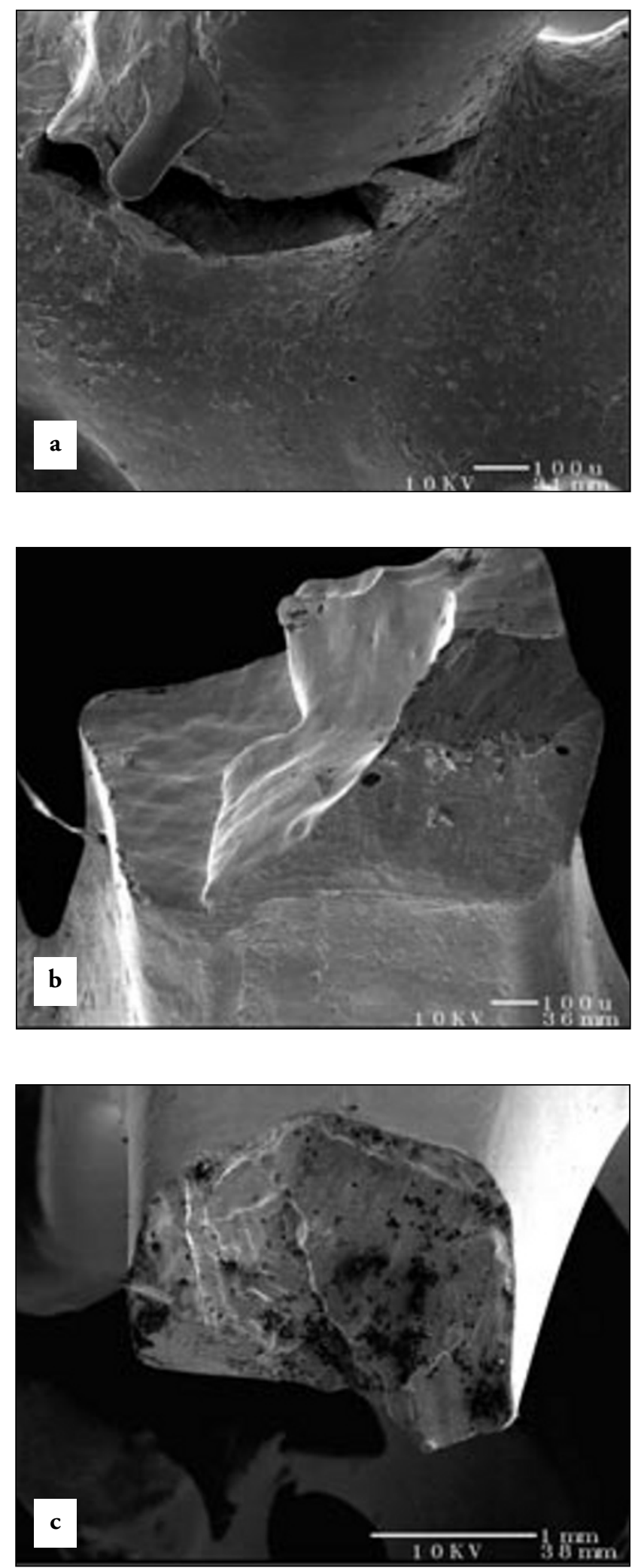

Figure 1 Failures in silicon-deoxidized casting alloys indicating brittle behaviour. Figures (a) and (b) are prong failures while (c) is a shank failure the development of a simplified model for liquid and solid yellow karat gold alloys containing silicon in temperature ranges between the liquidus and slightly below the solidus, (2) the use of the simplified alloy model to calculate the severity of silicon microsegregation in solidifying yellow karat gold alloys and (3) comparisons of observed microsegregation with predictions based on the simplified alloy model.

\section{YELLOW KARAT GOLD ALLOY MODEL}

Casting alloys are formulated to be successfully melted, cast into moulds, and solidified into desired shapes. They have evolved in the jewelry industry with primary emphasis on karat and colour as well as casting and finishing characteristics. In yellow karat gold alloys containing major concentrations of gold, copper, and silver with minor levels of zinc, the alloying elements are completely soluble in the liquid state. Also, gold, silver, copper, and zinc are so mutually soluble at elevated temperatures in the solid state that complex metallurgical reactions between these elements are not commonly observed in jewelry alloys. Quasibinary phase diagrams at constant caratages of 10,14 , and $18 \mathrm{~K}$ in the $\mathrm{Au}-\mathrm{Ag}-\mathrm{Cu}$ system demonstrate complete solubility in the solid state just below the solidus temperatures (5). Zinc is a minor alloying element in karat golds and the concentration levels that are usually present are low enough for zinc not to create any metallurgical complexity (5). In the simplified alloy model used in this investigation, gold, silver, and zinc atoms are considered to be equivalent to copper since copper is the major component in $10 \mathrm{~K}$ and $14 \mathrm{~K}$ alloys on an atomic percentage basis and complex metallurgical reactions do not occur between them. This is a bold assumption but it will be demonstrated to be highly instructive and reasonably valid.

Silicon is soluble in pure gold, copper, silver, and zinc in the liquid state and it is essentially insoluble in these elements in the solid state. Pure copper can dissolve up to a maximum of about $5.25 \mathrm{wt} \%$ of silicon as can be seen in the $\mathrm{Cu}-\mathrm{Si}$ equilibrium phase diagram given in Figure 2 (6). Above this concentration, many complex $\mathrm{Cu}-\mathrm{Si}$ phases may exist depending on silicon concentration and temperature. Normandeau (2) adjusted silicon in experimental 10, 14 , and $18 \mathrm{~K}$ gold alloys based on the assumption that increasing amounts of gold reduce the solubility of 


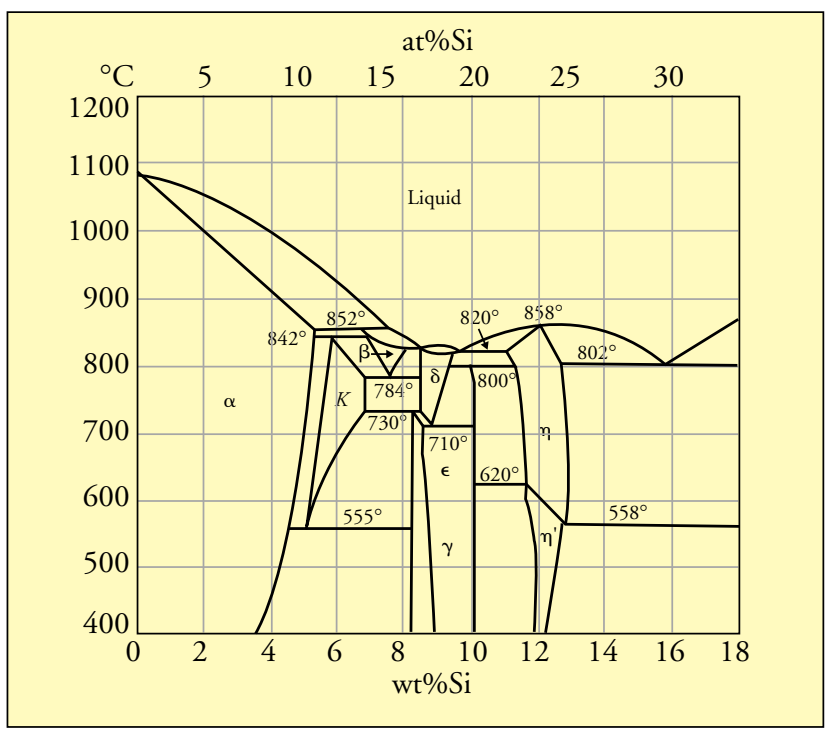

Figure 2 Copper-rich portion of the Cu-Si binary phase diagram (6)

silicon in $(\mathrm{Au}-\mathrm{Ag}-\mathrm{Cu})$ alloys. The current investigation assumes that silver and zinc also reduce the solubility of silicon in karat gold jewelry alloys in the same manner as does gold. This investigation is an attempt to observe and explain the detailed behaviour of silicon in (Au-Ag-Cu-Zn)-Si alloys using some simplifying metallurgical assumptions.

\section{EQUILIBRIUM PHASE DIAGRAM MODIFICATIONS BASED ON AN ALLOY MODEL}

As stated above, the key assumption used throughout this investigation is that gold, silver, copper, and zinc are completely compatible with each other and equivalent to copper. With this assumption, a $\mathrm{Cu}-\mathrm{Si}$ equilibrium phase diagram can be modified to a $(\mathrm{Cu}-$ $\mathrm{Au}-\mathrm{Ag}-\mathrm{Zn}$ )-Si phase diagram or a $\mathrm{Cu}^{\mathrm{a}}-\mathrm{Si}$ quasibinary phase diagram. For clarity, 14 karat (Cu-Au-Ag-Zn) alloys are designated as $\mathrm{Cu}^{\mathrm{a}}$ alloys in the rest of this article where $\mathrm{Cu}^{\mathrm{a}}$ represents the collection of copper, gold, silver, and zinc components in the alloy.

Phase boundary adjustments have been made to the $\mathrm{Cu}-\mathrm{Si}$ binary equilibrium diagram based on estimates of the reported effects of gold, silver, and zinc on the solubility of silicon in copper to obtain a schematic $\mathrm{Cu}^{\mathrm{a}}-\mathrm{Si}$ phase diagram. Data reported for the ternary $\mathrm{Au}-\mathrm{Cu}-\mathrm{Si}$ phase diagram was used to determine the solid solubility of silicon in $\mathrm{Au}-30$ wt $\% \mathrm{Cu}$ as $0.093 \mathrm{wt} \%$ silicon at $349^{\circ} \mathrm{C}(7)$. In $14 \mathrm{~K}$

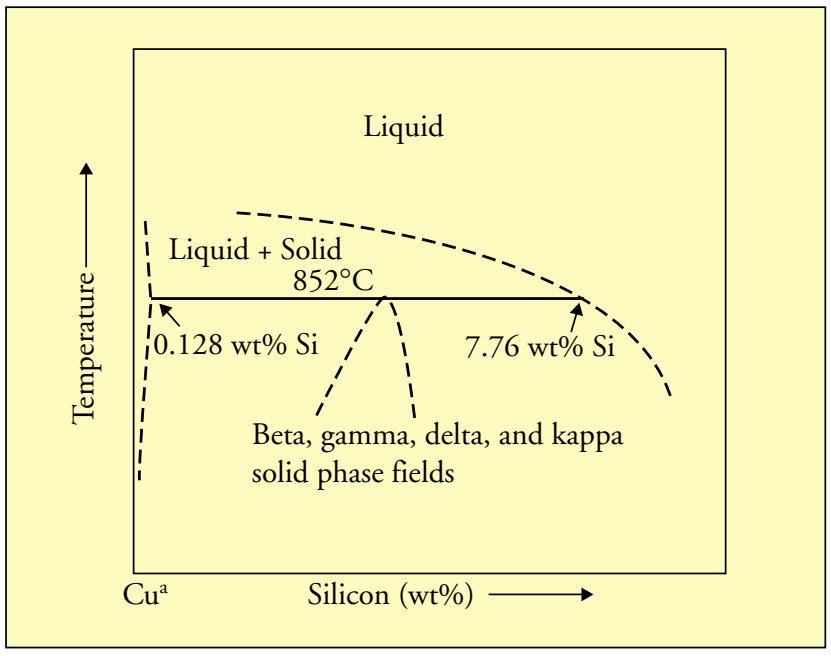

Figure 3 Schematic of $C u^{a}$-Si phase diagram where $C u^{a}$ stands for 14 karat (Cu-Au-Ag-Zn) gold alloys. This is a modified $\mathrm{Cu}$-Si phase diagram. Note the extremely low solubility of silicon in the $\mathrm{Cu}^{a}$ solid phase

yellow gold alloys, $30 \mathrm{wt} \%$ is a very typical concentration level for copper. From the $\mathrm{Cu}-\mathrm{Si}$ binary phase diagram, the solubility of silicon in copper is reported to be $3.8 \mathrm{wt} \%$ at $394^{\circ} \mathrm{C}$ (8). This suggests that the solubility of silicon in $\mathrm{Cu}^{\mathrm{a}}$-Si alloys at any other temperature can be estimated to be $0.093 / 3.8$ or 2.45 per cent of the solubility of silicon in binary $\mathrm{Cu}-\mathrm{Si}$ alloys. It should be remembered that it is assumed that gold, copper, silver, and zinc are all equivalent to each other. The adjusted maximum solid solubility of silicon in a $\mathrm{Cu}^{\mathrm{a}}-\mathrm{Si}$ alloy system with a peritectic temperature assumed to be $852^{\circ} \mathrm{C}$ is estimated as $0.0245 \times 5.25 \mathrm{wt} \%$ silicon or 0.128 wt $\%$ silicon.

Figure 3 is a schematic phase diagram for a $\mathrm{Cu}^{\mathrm{a}}-$ $\mathrm{Si}$ alloy system based on modifications to the equilibrium $\mathrm{Cu}-\mathrm{Si}$ phase diagram. The critical points are the maximum solid solubility of silicon in 14 karat gold alloys of $0.128 \mathrm{wt} \%$ at a peritectic temperature of $852^{\circ} \mathrm{C}$ and the corresponding 7.76 $\mathrm{wt} \%$ silicon in the liquid which is in equilibrium with the solid at the peritectic temperature. No adjustments were made to the $7.76 \mathrm{wt} \%$ silicon concentration in the liquid because no assumptions were made in the alloy model regarding the effect of gold, silver, and zinc on the solubility of silicon in liquid copper. It is assumed that there are no complicating metallurgical effects in the liquid state. As shown in the experimental results, quantitative electron microprobe work supports this estimation with a solid solubility of silicon in $14 \mathrm{~K}$ yellow gold alloy at about $0.1 \mathrm{wt} \%$. 


\section{THE SOLIDIFICATION MODEL}

During freezing, alloying elements tend to partition and 'unmix' themselves. The resulting microsegregation that can be observed on a polished and etched metallographic sample is called 'coring' and occurs across the spaces between dendrite arms. The simplest model that is customarily used to predict the extent of unmixing during solidification is called the ideal, non-equilibrium solidification model. It assumes that there are no undercooling effects and all alloying elements are completely and uniformly mixed in the liquid at all times during freezing. A key assumption in the model is that there is no movement of alloying elements within the solid by atomic diffusion. As a consequence, different concentrations of alloying elements that are frozen into the solid as solidification progresses remain in place and are detectable in solid samples. Due to the lack of available literature on detailed solidification characteristics of 14 karat yellow gold alloys, it was decided to use this simplistic model while fully aware of its shortcomings. Detailed descriptions of solidification phenomena can be found in Flemings' book entitled, 'Solidification Processing' (9).

According to the ideal, non-equilibrium solidification model, microsegregation can be estimated in a two component (binary) alloy by the Gulliver-Scheil equation (9):

where

$$
\mathrm{C}_{\mathrm{s}}=\mathrm{k} \mathrm{C}_{\mathrm{o}}\left(1-\mathrm{f}_{\mathrm{s}}\right) \mathrm{k}-1
$$

$\mathrm{f}_{\mathrm{s}}=$ fraction of solid formed

$\mathrm{k}$ = partition coefficient, and is equal to $\mathrm{C}_{s} / \mathrm{C}_{\mathrm{L}}$, where $\mathrm{C}_{\mathrm{s}}$ and $\mathrm{C}_{\mathrm{L}}$ are the respective concentrations of segregating element in the solid and liquid which are in equilibrium. $\mathrm{k}$ is assumed to be constant during freezing

$\mathrm{C}_{\mathrm{o}}=$ initial concentration of segregating element in the alloy

The Gulliver-Scheil equation is based on one basic principle: a simple material balance. It is based on the fact that a certain quantity of an alloying element is rejected by a solid phase as it forms in a solidifying system and whatever is left over is retained by the liquid. Nothing is created, nothing is lost, and nothing is destroyed. It does not concern itself with variations in cooling rates and the effects of cooling rate on grain size and dendrite arm spacing. As stated in the Gulliver-Scheil assumptions (9), solute accumulates in the freezing liquid in a steady, continuous manner. Although it is known that diffusion of alloying elements is occurring in the frozen solid during solidification, this diffusion is negligible when compared to the magnitude of solute increases in the liquid.

During early stages of freezing at low fractions of solid, the information supplied by the Gulliver-Scheil equation is interesting but it can also be directly found on a phase diagram. The most important information from the Gulliver-Scheil equation comes at the end of the freezing cycle when the fraction of solid in a solidifying system is approaching unity. The equation tells us how the composition of the liquid is changing and suggests what might possibly happen when the last bit of freezing occurs. The critical point is that the Gulliver-Scheil equation will predict the potential appearance of non-equilibrium phase(s) and an equilibrium phase diagram will not.

Microsegregation in binary alloys is simple to evaluate because values for the partition coefficient, $\mathrm{k}$, are available from equilibrium phase diagrams for use in the Gulliver-Scheil equation. Values for the composition of solid and liquid in equilibrium with each other are picked off the ends of horizontal tie lines across solid plus liquid phase field at temperatures of interest. If solidus and liquidus boundaries are close to being straight lines, $\mathrm{k}$ can be assumed to be constant in value and microsegregation calculations can be easily performed.

Unfortunately, for casters of precious metal alloys, the Gulliver-Scheil equation is difficult to apply because values for partition coefficient, $\mathrm{k}_{\mathrm{x}}$, do not exist for $\mathrm{Cu}^{\mathrm{a}}-\mathrm{X}$ alloys, where $\mathrm{X}$ can be one of several types of deoxidizers that are used in karat golds. Ternary and quaternary phase diagrams which include experimentally determined tie lines across solid-liquid phase fields are necessary to establish values for partition coefficients. It is unfortunate that very few such phase diagrams exist. Even though comprehensive phase diagrams for $\mathrm{Cu}^{\mathrm{a}}$-Si alloys do not exist, GulliverScheil calculations have been performed in this study to evaluate silicon microsegregation by using an estimate for silicon partition coefficient, $\mathrm{k}_{\mathrm{si}}$.

The estimated value for $k_{s i}$ was determined from the modified phase diagram presented in Figure 3. The peritectic horizontal at $852^{\circ} \mathrm{C}\left(1566^{\circ} \mathrm{F}\right)$ in Figure 3 indicates that $\mathrm{Cu}^{\mathrm{a}}$ solid containing $0.128 \mathrm{wt} \%$ silicon is in equilibrium with $\mathrm{Cu}^{\mathrm{a}}$ liquid containing $7.76 \mathrm{wt} \%$ silicon. Using these values, $\mathrm{k}_{\mathrm{si}}$ is estimated to be equal to $0.128 / 7.76=0.0165$.

Grice (4) has determined the liquidus and solidus temperatures for $9 \mathrm{~K}$ yellow gold alloys which contain increasing amounts of silicon. In Grice's published 


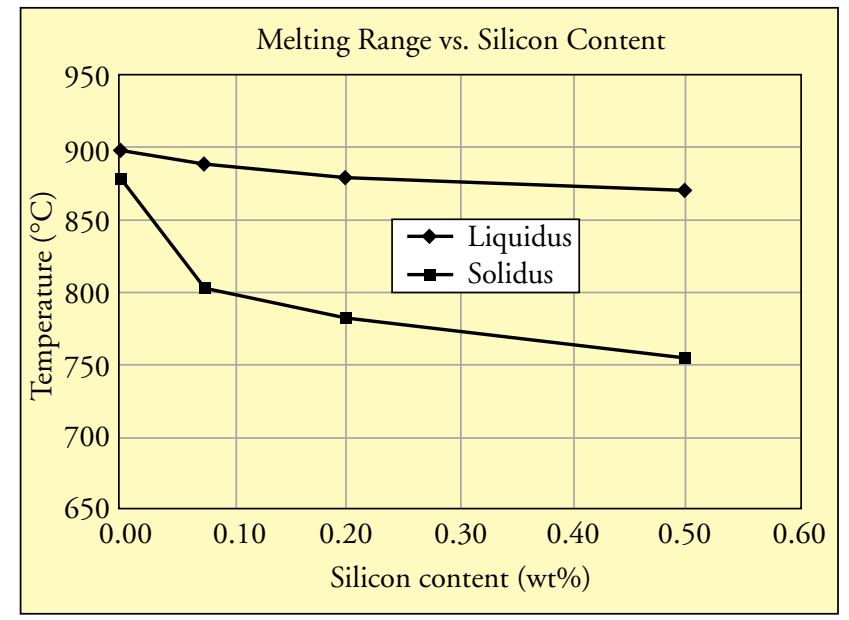

Figure 4 Melting range versus silicon content for $9 K$ gold alloys. Data modified from Grice's results (4)

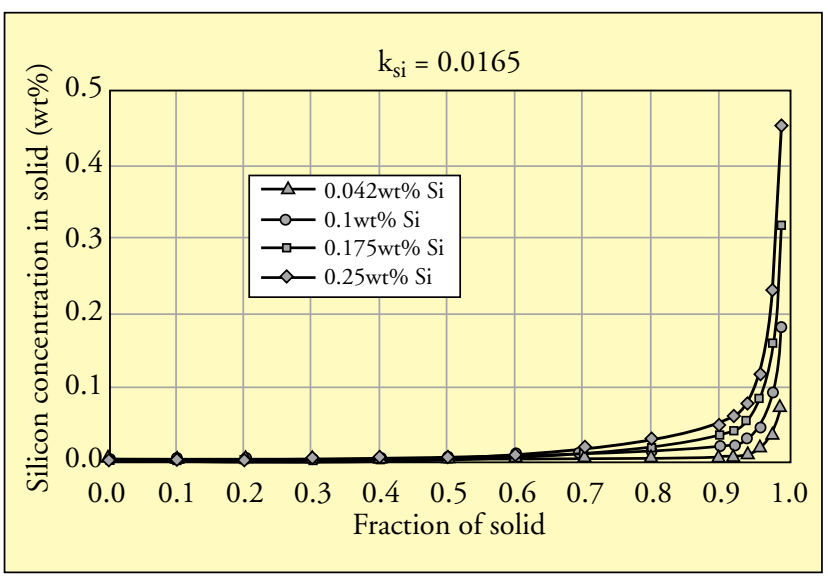

Figure 5 Distribution of silicon in the solid phase in $\mathrm{Cu}^{a}$ alloy during freezing as predicted by the Gulliver-Scheil equation

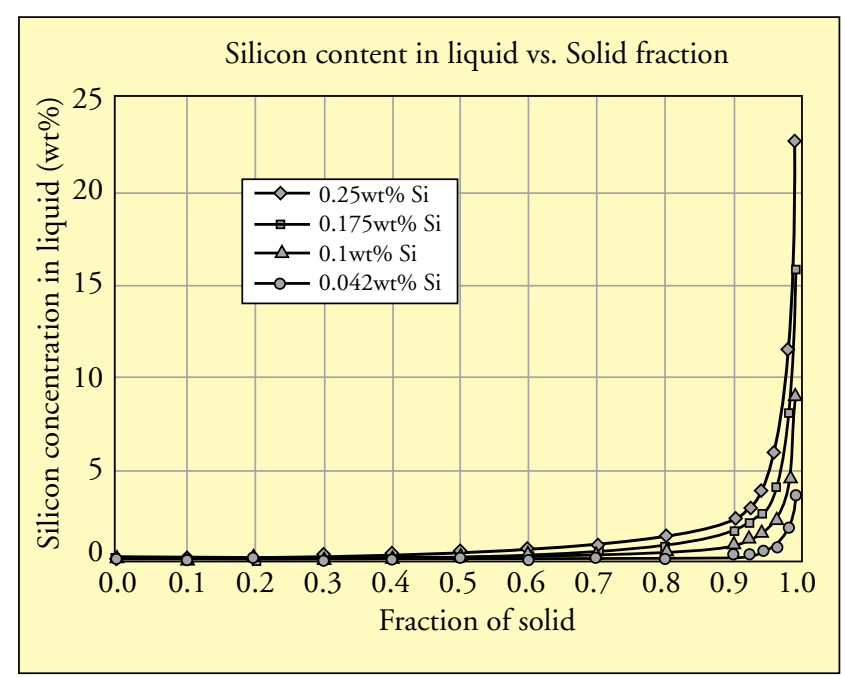

Figure 6 Silicon distribution in the liquid phase according to the Gulliver-Scheil equation study, temperature is plotted against nominal silicon content. This plot looks like a phase diagram although it is not a true equilibrium diagram that would be determined by lengthy, careful experiments. However, this data can be used to estimate a value for the partition coefficient of silicon in 9K yellow gold alloy.

Grice's liquidus and solidus temperature data was replotted as temperature versus measured silicon content in the alloy. Results are presented in Figure 4. A horizontal tie line at $870^{\circ} \mathrm{C}\left(1598^{\circ} \mathrm{F}\right)$ indicates that $\mathrm{k}_{\mathrm{si}}=\mathrm{C}_{\mathrm{s}} / \mathrm{C}_{\mathrm{L}}$ would have a value of $0.01 / 0.5=0.02$. The higher $\mathrm{k}_{\mathrm{si}}$ value for Grice's $9 \mathrm{~K}$ yellow gold alloy compared with that for our $14 \mathrm{~K}$ alloy indicates a higher solid solubility for silicon in the lower caratage gold alloy than in our $14 \mathrm{~K}$ gold alloy. Previous investigation has indicated that this is indeed the case (2).

Figure 5 describes the distribution of silicon in the solid phase of a freezing $14 \mathrm{~K} \mathrm{Cu}^{\mathrm{a}}$ alloy according to the Gulliver-Scheil equation for a $\mathrm{k}_{\mathrm{si}}$ value of 0.0165 . Four different initial, average silicon compositions are assumed for the alloy. Note the dramatic increases in silicon concentration in the solid when the fraction of solid starts to exceed 0.9 .

Figure 6 is similar to Figure 5 except that the silicon concentration in the liquid phase is plotted versus the fraction of solid. Mathematically, the graph predicts that silicon levels in the liquid can increase to as high as 15 to $20 \%$ during the late stages of freezing. Does this really happen? No, of course not. In a real world situation, silicon concentration in the liquid would be increasing as the casting is cooling. At some point, a temperature corresponding to an invariant eutectic or peritectic reaction would be reached. The cooling would become arrested at this temperature and the liquid would transform into phases which would be dictated by the particulars of the invariant reaction.

\section{EXPERIMENTAL TRIALS}

A $14 \mathrm{~K}$ yellow gold, silicon-deoxidized casting alloy was directionally solidified in a hot mould approximately $1 \frac{1 / 2}{2}$ inches $(38 \mathrm{~mm})$ in diameter and $6^{1 / 2}$ inches $(165 \mathrm{~mm})$ long. The mould was made from gypsum bonded investment and heated to about $1200^{\circ} \mathrm{F}\left(649^{\circ} \mathrm{C}\right)$. It was placed on a water-cooled chill and filled with metal by a direct pour through its open top. After filling, the exposed top of the metal was covered with an insulating blanket. In this way, a sample of material with large columnar grains with known orientations was produced for use in subsequent studies. 


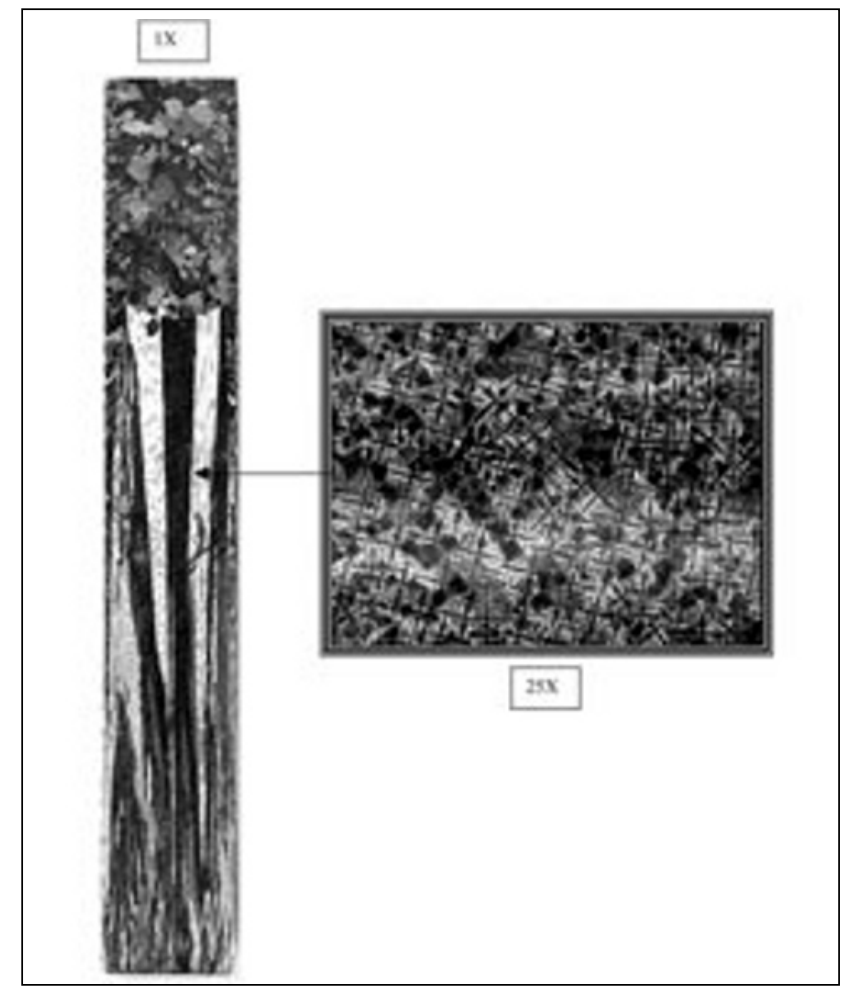

Figure 7 Macrostructure of a directionally solidified $14 \mathrm{~K}$ yellow gold alloy containing $0.046 \mathrm{wt} \%$ silicon. The inset shows the dendritic microstructure present in one of the well-developed columnar grains

Figure 7 illustrates the macrostructure of the directionally solidified sample. It shows the long, welldeveloped columnar grains extending along most of the sample's length. The grains are approximately $1 / 8$ to $1 / 4$ inch $(3-6.4 \mathrm{~mm})$ in diameter at a location of about 3 to 4 inches $(75-100 \mathrm{~mm})$ above the water-cooled chill. The grain diameter increases from the bottom of the casting to the top in a fashion that is very typical of directionally frozen castings.

\section{EXPERIMENTAL RESULTS}

Metallographic samples with transverse orientations within the columnar zone about 3 to 4 inches (75$100 \mathrm{~mm}$ ) above the chill were selected and prepared for electron microprobe analyses. The selection of transverse orientations allowed observations on dendritic structures with fixed orientations. Structures were well-developed with relatively large dendrite arm spacings at locations where samples were removed. Figure 8 is a backscattered electron image of the dendrites. The arms in the plane of the photomicrograph are secondary arms. Primary arms

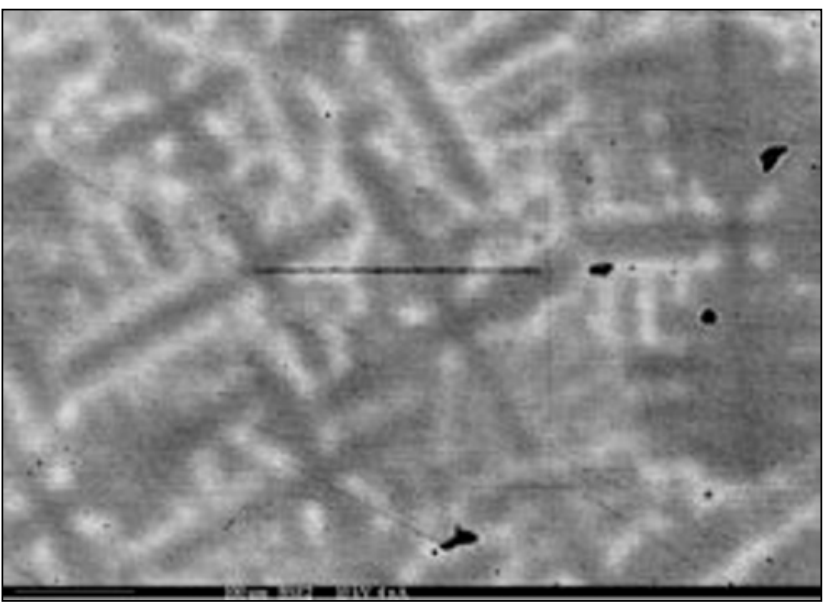

Figure 8 Backscattered electron image of the dendritic microstructure in the directionally solidified alloy. Areas with higher average atomic number appear light in colour. The dark line in the middle is the electron microprobe trace

are perpendicular to the plane of the photomicrograph and are located at the intersections of secondary arms.

The distribution of alloying elements around dendrite arms was qualitatively evaluated with $\mathrm{x}$-ray mapping techniques using wavelength dispersive spectroscopy (WDS). In the images of Figure 9, lighter coloured areas contain higher concentrations of the element being observed, and darker areas are regions of lower concentrations of the element under observation. The images presented in Figure 9 indicate that gold, zinc, and silicon are uniformly distributed throughout the microstructure. The gold and zinc data is reasonably acceptable. However, the silicon is present in such low concentrations that this analytical technique is neither valid nor appropriate. On the other hand, copper was found to be present at the core of dendrites at higher concentrations. Interdendritic locations are leaner in copper. Silver behaves in a reverse manner. Dendrite cores are depleted in silver and interdendritic areas are rich in silver. The x-ray maps correlate well with optical and backscattered images. However, $\mathrm{x}$-ray mapping provides specific information about which elements are in a particular segregation pattern whereas optical and backscattered images do not identify the segregating elements that are responsible for distribution patterns in a particular array of dendrite arms.

The $\mathrm{x}$-ray mapping results with WDS techniques were confirmed by time-of-flight secondary ion mass spectroscopy (TOF-SIMS). Figure 10 contains TOFSIMS images and confirms that silver and copper are non-uniformly distributed around dendrite arms. The 


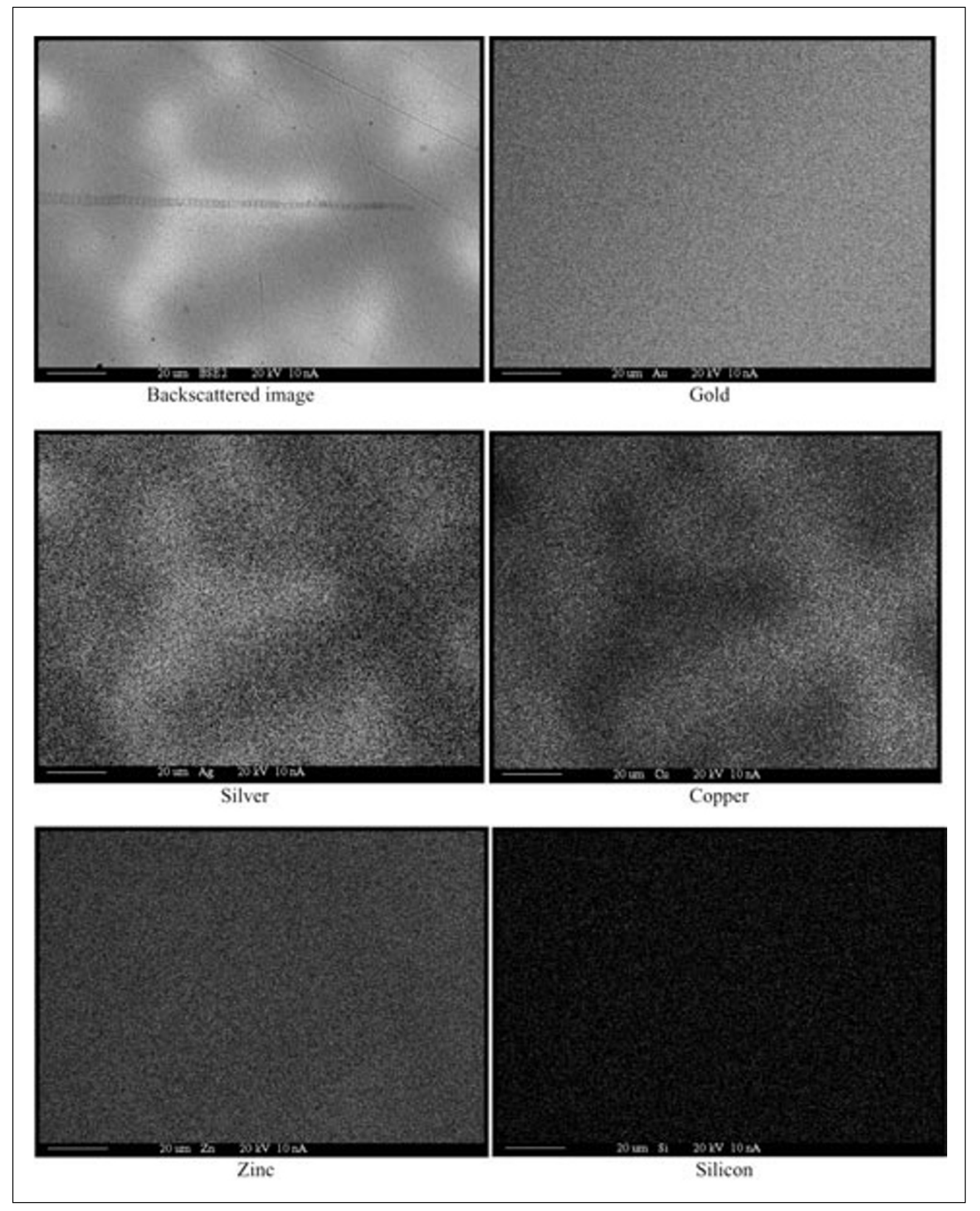

Figure $9 X$-ray mapping images showing the distribution of alloying elements in and around the dendrites 


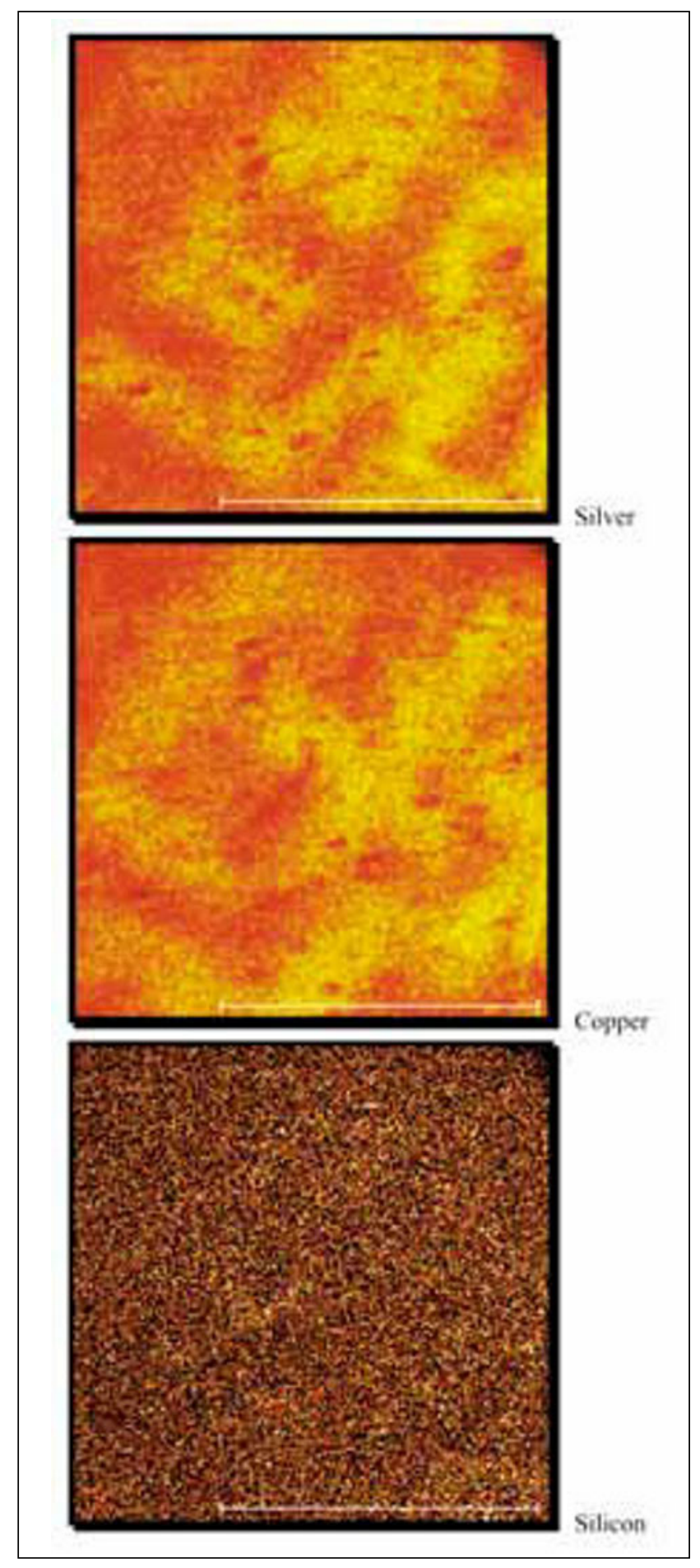

Figure 10 Time-of-flight secondary ion mass spectroscopic (TOFS-SIMS) images showing distribution of silver, copper, and silicon around dendritic arms

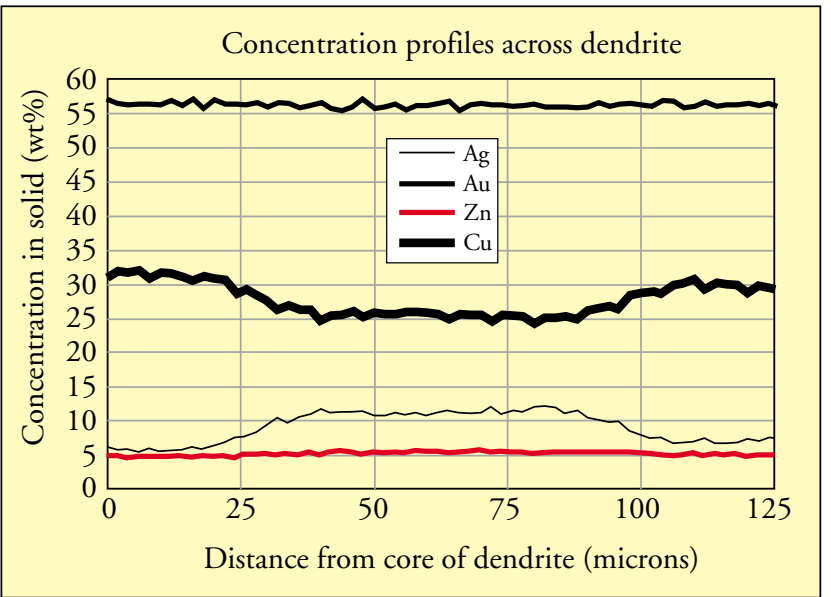

Figure 11 Concentration profiles across dendrite. Electron microprobe work done by Operhall Laboratories

analyst reported that gold and silicon displayed uniform distributions but the silicon levels were too low for valid conclusions to be reached. As in x-ray mapping, light areas are regions of high concentration and dark areas are regions of low concentration of the elements that are being observed.

Quantitative analyses at various locations within the dendritic structures were performed by electron microprobe techniques at two different laboratories. The metallographic sample used for backscatter imaging in Figure 8 was also used for this exercise. The nominal composition of the alloy is given in Table 1. The horizontal line in the photomicrograph in Figure 8 indicates the path that the microprobe beam followed across the sample.

Microprobe results using WDS analytical methods are presented in Figures 11 and 12. The results obtained from Operhall Laboratories, Figure 11, can be summarized as follows:

- There is no tendency for gold and zinc to severely segregate.

Table 1 The Nominal Composition of the Sample Used for Backscatter Imaging

$\begin{array}{cc}\text { Element } & \text { Nominal concentration, wt\% } \\ \text { Gold } & 58.24 \\ \text { Copper } & 28.99 \\ \text { Silver } & 8.02 \\ \text { Zinc } & 4.70 \\ \text { Silicon } & 0.046^{*}\end{array}$

* Actual Composition 


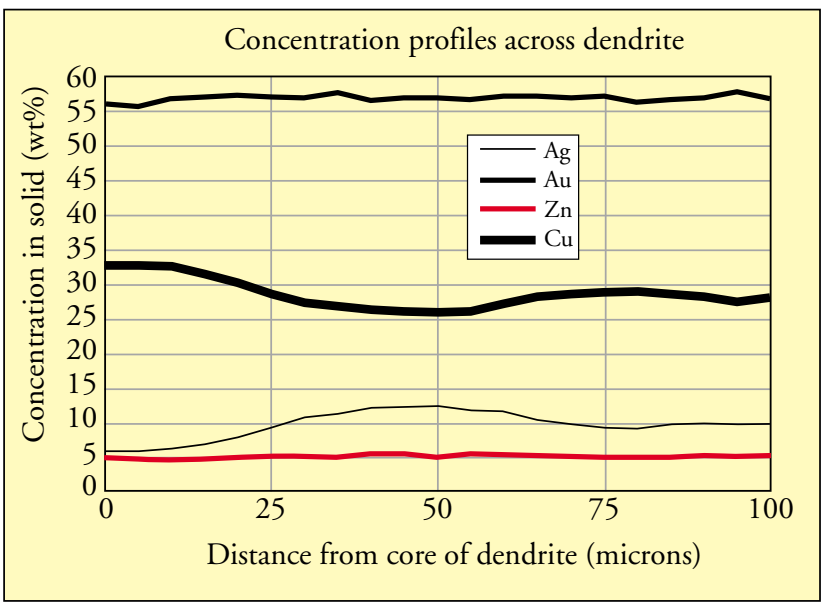

Figure 12 Concentration profiles across dendrite. Electron microprobe work performed by Evans East

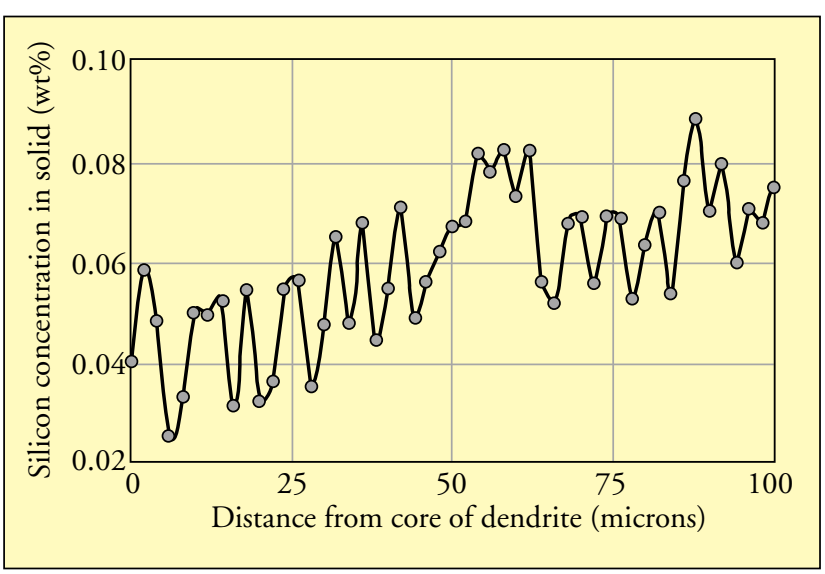

Figure 13 Silicon concentration profile across dendrite (Operhall Laboratories)

- Copper and silver segregate in a reverse manner; as copper concentration decreases, silver concentration increases.

- Silicon concentration increases from low values in dendrite cores to high values at interdendritic locations as shown in Figure 13.

Similar microprobe data from another laboratory, Evans-East, confirms the observations from the Operhall Laboratory data. However, silicon was observed to be more severely segregated in data obtained by Evans-East as shown in Figure 14. As stated previously, quantitative electron microprobe work supports the estimate of the solid solubility of silicon in $14 \mathrm{~K}$ yellow gold alloy at about $0.1 \mathrm{wt} \%$. No silicon-rich particles were detected in the directionally solidified $14 \mathrm{~K}$ gold alloy containing $0.046 \mathrm{wt} \%$ silicon.

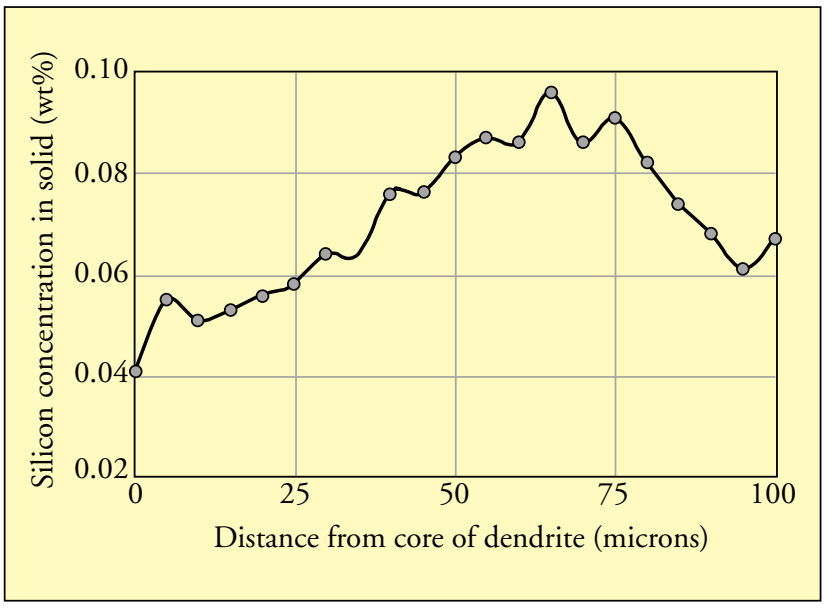

Figure 14 Silicon concentration profile across dendrite (Evans East)

\section{ANALYSIS AND DISCUSSION}

Microprobe measurements on metallographic samples with known dendritic orientations indicate that copper, silver, and silicon are the segregated elements in a $14 \mathrm{~K}$ yellow gold jewelry alloy. The concentration differences observed are summarized in Table 2 . The plus and minus signs indicate the direction of concentration change from core to interdendritic locations. A positive value indicates increasing, richer compositions, while a negative value means decreasing, leaner compositions. The severity of silicon segregation (138 per cent) was used to try to explain observations made by Grice and Normandeau in $9 \mathrm{~K}$ and $14 \mathrm{~K}$ yellow gold alloys containing various amounts of silicon.

In $14 \mathrm{~K}$ yellow gold alloys containing actual concentrations of 0.162 and $0.211 \mathrm{wt} \%$ silicon, Normandeau observed particles that were rich in copper and silicon on fracture surfaces. Tensile samples were reported to be very brittle. Referring back to Figures 5 and 6 which describe how silicon can accumulate in the solid and liquid phases of a freezing mass, the Gulliver-Scheil calculations indicate that silicon concentrations can reach levels of 15 to $20 \%$ in

Table 2 Concentration Changes from Core to Interdendritic Locations

$\begin{array}{cc}\text { Element } & \text { Concentration difference, \% } \\ \text { Copper } & -23 \\ \text { Silver } & +138 \\ \text { Silicon } & +138\end{array}$


Table 3 Unexpected Phases Observed by Grice in 9K Gold Alloys Containing Silicon (4)

\begin{tabular}{lccccc} 
& \multicolumn{6}{c}{ Silicon in alloy grain, wt\% } \\
Microstructural Phases & 0.00 & 0.075 & 0.20 & 0.50 & $>0.75$ \\
Phase A & P & P & P & P & P \\
Phase B & & & $P$ & $P$ & $P$ \\
P = Present & & & & &
\end{tabular}

the liquid at late stages of solidification for the levels of silicon concentration reported by Normandeau. The modified $\mathrm{Cu}^{\mathrm{a}}-\mathrm{Si}$ phase diagram presented in Figure 3 indicates that when silicon exceeds $7.76 \mathrm{wt} \%$ in the liquid, many different intermediate phases can appear in solidification structures. It is impossible to even guess which of several phases might form, but it is prudent to be concerned about them and not be surprised by their appearance.

In similar fashion, Grice reported the appearance of unexpected phases in his work with $9 \mathrm{~K}$ gold alloys containing silicon. These observations are summarized in Table 3.

Energy dispersive $\mathrm{x}$-ray data reported by Grice indicates that Phase A is silver rich, and depleted in copper and contains silicon with a uniform microstructure. Phase B is copper rich with higher silicon levels. However, a closer examination of this phase reveals that microstructurally it is not a single phase but has a duplex microstructure. Is it a peritectic or a eutectic?

Normandeau (2) has recommended the following ranges of silicon additions in $10 \mathrm{~K}, 14 \mathrm{~K}$, and $18 \mathrm{~K}$ yellow gold investment casting formulations based on (a) sudden loss of ductility in the castings and (b) combined gold and silver content in the alloy chemistry:

$$
\begin{aligned}
& \text { 10KY: } 0.15-0.35 \mathrm{wt} \% \mathrm{Si} \\
& \text { 14KY: } 0.09-0.12 \mathrm{wt} \% \mathrm{Si} \\
& \text { 18KY: } \quad<0.05 \mathrm{wt} \% \mathrm{Si}
\end{aligned}
$$

Grice (4), as previously mentioned, had noted hot tearing due to the presence of silicon-rich phase B which occurred in his $9 \mathrm{~K}$ yellow gold alloy at or above $0.2 \mathrm{wt} \%$ silicon.

Based on the solidification model used in this investigation, an effort was made to estimate the ranges of silicon in $14 \mathrm{~K}$ yellow gold alloy which might safely be used without creating embrittling phases in the microstructure. The Gulliver-Scheil equation can be used to estimate an initial concentration of silicon in the karat gold which will not become so severely

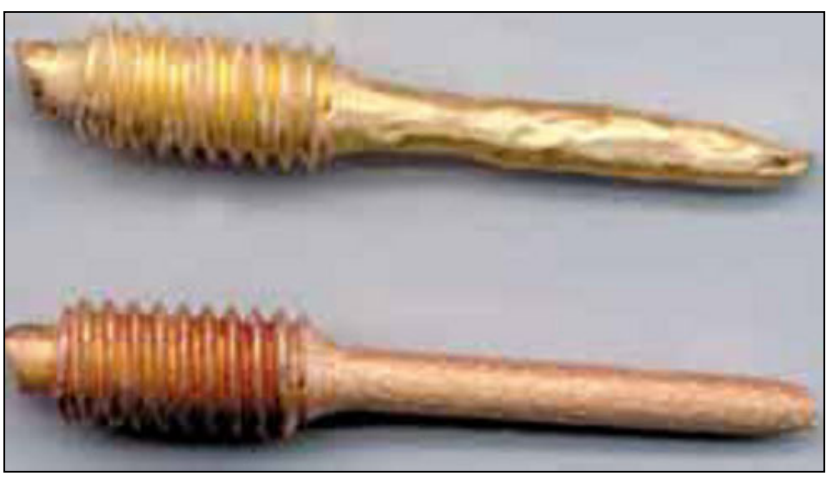

Figure 15 Fractured tensile specimens of silicon-deoxidized (top) and grain-refined(bottom) alloys showing gross, orange-peel effect on silicon-deoxidized alloy due to large grains

segregated during freezing that large quantities of silicon-rich particles are precipitated. The modified $\mathrm{Cu}^{\mathrm{a}}-\mathrm{Si}$ phase diagram suggests that silicon-rich particles will form when the liquid phase exceeds 7.76 wt $\%$ silicon. Engineering judgement coupled with some practical operating experience can be used to interpret the results of Gulliver-Scheil calculations.

For example, if an alloy contains $0.08 \mathrm{wt} \%$ silicon, the Gulliver-Scheil equation predicts that the silicon concentration in the freezing liquid reaches $7.76 \mathrm{wt} \%$, when the alloy is $99 \%$ solid. In a similar fashion, an initial concentration of $0.04 \mathrm{wt} \%$ silicon results in $7.76 \mathrm{wt} \%$ silicon in the freezing liquid when the fraction of solid is $99.5 \%$. These results suggest that initial silicon concentrations in the range of 0.04-0.08 $\mathrm{wt} \%$ in a $14 \mathrm{~K}$ yellow gold alloy would have a low probability of creating $\mathrm{Cu}-\mathrm{Si}$ intermetallic particles. Experience has shown that $0.04 \%$ silicon will produce clean, bright, and ductile castings.

These observations lead to the following conclusions. Silicon has a reduced solubility in solid $\mathrm{Cu}^{\mathrm{a}}$ alloys compared to its solubility in pure copper. This reduced solubility results in low values of the partition coefficient for silicon in $\mathrm{Cu}-\mathrm{Au}-\mathrm{Ag}-\mathrm{Zn}$ alloys. The dynamics of non-equilibrium freezing can promote the build-up of silicon in the freezing liquid phase to such an extent that unexpected, silicon-rich phases and compounds can appear in the solidification structure. These phases can have deleterious effects on mechanical properties and limit the use of certain types of alloying elements in $\mathrm{Cu}-\mathrm{Ag}-\mathrm{Zn}-\mathrm{Au}$ families of alloys.

This investigation was found to have a practical application with grain-refined alloys. Typically, the performance of iridium as a grain refiner in silicondeoxidized $14 \mathrm{~K}$ yellow gold alloys has been less than 
satisfactory for industrial applications. Grain refining is erratic and the presence of silicide intermetallic compounds in the microstructure which appear on highly polished surfaces render these alloys practically useless.

By developing other methods for deoxidation, iridium has been successfully used to achieve reliable, consistent grain refining in a $14 \mathrm{~K}$ yellow gold jewelry alloy. Increases in tensile strength, ductility, and a reduction in metallurgical defects have been achieved by the use of a grain-refined alloy. A recent article in Gold Technology (10) provides a complete description of this work.

\section{CONCLUSIONS}

1 In precious metal alloy systems, low values of partition coefficient, $k$, should be a warning that larger than expected degrees of microsegregation are likely.

2 Using two different methods of estimation, values of 0.02 and 0.0165 were obtained for the silicon partition coefficient in $9 \mathrm{~K}$ and $14 \mathrm{~K}$ gold alloys respectively.

3 Using the ideal, non-equilibrium solidification model, it is estimated that a safe range for silicon concentration in 14 karat gold jewelry which will not result in the extensive formation of silicon-rich particles lies approximately in the range of 0.04-0.08 wt $\%$.

4 Copper, silver, and silicon were found to be the most severely segregated elements in $14 \mathrm{~K}$ jewelry alloys.

\section{ACKNOWLEDGEMENTS}

The authors wish to express their deep appreciation to their co-workers for their assistance in this investigation. These individuals include Mrs Linda Jambon for manuscript assistance and Mr David Allen and $\mathrm{Mr}$ John Butler for technical support in performing experiments. Finally, Dr Aldo Reti of Handy and Harman provided assistance with silicon analysis.

\section{ABOUT THE AUTHORS}

John McCloskey is Executive Director of Metals Division at Stuller Settings. $\mathrm{He}$ was awarded undergraduate and graduate degrees in Metallurgy by the Massachusetts Institute of Technology, Cambridge, Massachusetts, USA. He has over 30 years of liquid metals processing experience in the ferrous, nonferrous, and precious metals industries.

Shankar Aithal is Team Leader in the Technology Department at Stuller Settings. He has a doctorate in Materials Science from Oregon Graduate Institute of Science and Technology, Beaverton, Oregon, USA. His areas of experience include physical metallurgy of ferrous and precious metals and materials characterization using $\mathrm{x}$-ray and electron beams.

Randy Welch is Metals Coordinator in the Technology Department at Stuller Settings. He has been involved in precious metal processing operations for over 19 years at Stuller Settings. His expertise includes investment casting and all aspects of fabricated metals operations.

\section{REFERENCES}

1 D. Ott, Proc. Santa Fe Symposium on Jewelry Manufacturing Technology, Met-Chem Research Inc., 1997, p. 188

2 G. Normandeau and R. Roeterink, Gold Technology, 15, April 1995, p. 4

3 G. Normandeau, private communication

4 S. Grice, Proc. Santa Fe Symposium on Jewelry Manufacturing Technology, Met-Chem Research Inc., 1999, p. 205

5 W.S. Rapson, Gold Technology, 4, May 1991, p. 16

6 'Smithells Metals Reference Book', ed. E.A. Brandes and G.B. Brook, Butterworth Heinemann, Oxford, UK, p. 11-241

7 'Phase Diagrams of Ternary Gold Alloys', A. Prince, G.V. Raynor, and D.S. Evans, The Institute of Metals, 1990, p. 243

8 'Phase Diagrams of Binary Copper Alloys', ed. P.R. Subramanian, D.J. Chakrabarti and D.E. Laughlin, ASM International, 1994, p. 398

9 M.C. Flemings, 'Solidification Processing', McGraw-Hill, New York, NY, 1974

10 J.C. McCloskey, P.R. Welch and S. Aithal, Gold Technology, 30, Winter 2000, p. 4 